\title{
O.S.P.
}

L'orientation scolaire et professionnelle

$36 / 1 \mid 2007$

Insertion, biographisation, éducation

\section{J. Guichard \& M. Huteau. Orientation et insertion professionnelle. 75 concepts clés}

Paris : Dunod

Françoise Bacher

\section{OpenEdition}

Journals

Édition électronique

URL : https://journals.openedition.org/osp/1339

DOI : $10.4000 /$ osp.1339

ISSN : 2104-3795

Éditeur

Institut national d'étude du travail et d'orientation professionnelle (INETOP)

Édition imprimée

Date de publication : 15 mars 2007

Pagination : 107

ISSN : 0249-6739

Référence électronique

Françoise Bacher, « J. Guichard \& M. Huteau. Orientation et insertion professionnelle. 75 concepts clés », L'orientation scolaire et professionnelle [En ligne], 36/1 | 2007, mis en ligne le 08 décembre 2009,

consulté le 18 janvier 2022. URL : http://journals.openedition.org/osp/1339 ; DOI : https://doi.org/

10.4000/osp.1339

Ce document a été généré automatiquement le 18 janvier 2022.

(c) Tous droits réservés 


\section{J. Guichard \& M. Huteau. Orientation et insertion professionnelle. 75 concepts clés}

Paris : Dunod

\section{Françoise Bacher}

\section{RÉFÉRENCE}

\section{Paris : Dunod}

1 L'ouvrage dirigé par Jean Guichard et Michel Huteau se présente comme un dictionnaire de concepts largement utilisés par tous ceux qui s'occupent d'orientation et d'insertion professionnelle.

2 Le format choisi, un nombre limité de concepts, permet de consacrer à chacun un article de quelques pages, 6 en moyenne, et ainsi de rappeler son origine et son évolution. Un index des notions très fourni permet de retrouver un beaucoup plus grand nombre de termes à l'intérieur de ces articles.

3 Les auteurs, qui ont tour à tour dirigé l'Institut national d'étude du travail et d'orientation professionnelle, sont particulièrement bien placés pour mener à bien cette entreprise très ambitieuse. Ils l'ont fait avec l'aide de plusieurs autres spécialistes, d'économie, de psychologie, de sociologie et de sciences de l'éducation : Jacques Aubret, Claude Dubar, Jean-François Germe, Michel Lallement, José Rose, Georges Solaux.

4 Le champ couvert est extrêmement large puisqu'il s'agit de tout ce qui concerne l'orientation et l'insertion professionnelle. La lecture des articles montre à quel point ces secteurs ont évolué au cours du temps et continuent d'évoluer de façon accélérée. Les problèmes rencontrés, les mesures institutionnelles destinées à en faciliter la solution sont en perpétuel changement. 
5 Les conceptions évoluent également très vite. On est passé de l'idée d'une orientation initiale, ponctuelle, à une conception de l'orientation tout au long de la vie, dans laquelle l'intéressé joue un rôle essentiel. On est passé d'un souci d'insertion relatif surtout aux jeunes et aux publics en difficulté à la notion d'une insertion professionnelle et personnelle concernant chacun, tout au long de sa vie, face à des changements devenus le lot commun.

6 Pour chaque concept, une traduction en anglais est proposée, ce qui devrait accroître encore l'intérêt de l'ouvrage. La difficulté à traduire certains concepts fait bien ressortir leur dépendance à l'égard des institutions existantes, propres à chaque pays.

7 L'ouvrage s'adresse à un public très large puisqu'il peut intéresser tous ceux qui s'occupent d'orientation et d'insertion professionnelle. Préciser le sens des concepts utilisés, les situer dans leur évolution, ne peut que favoriser le travail commun des personnes concernées qui viennent d'horizons très différents et ont des formations très différentes également. 